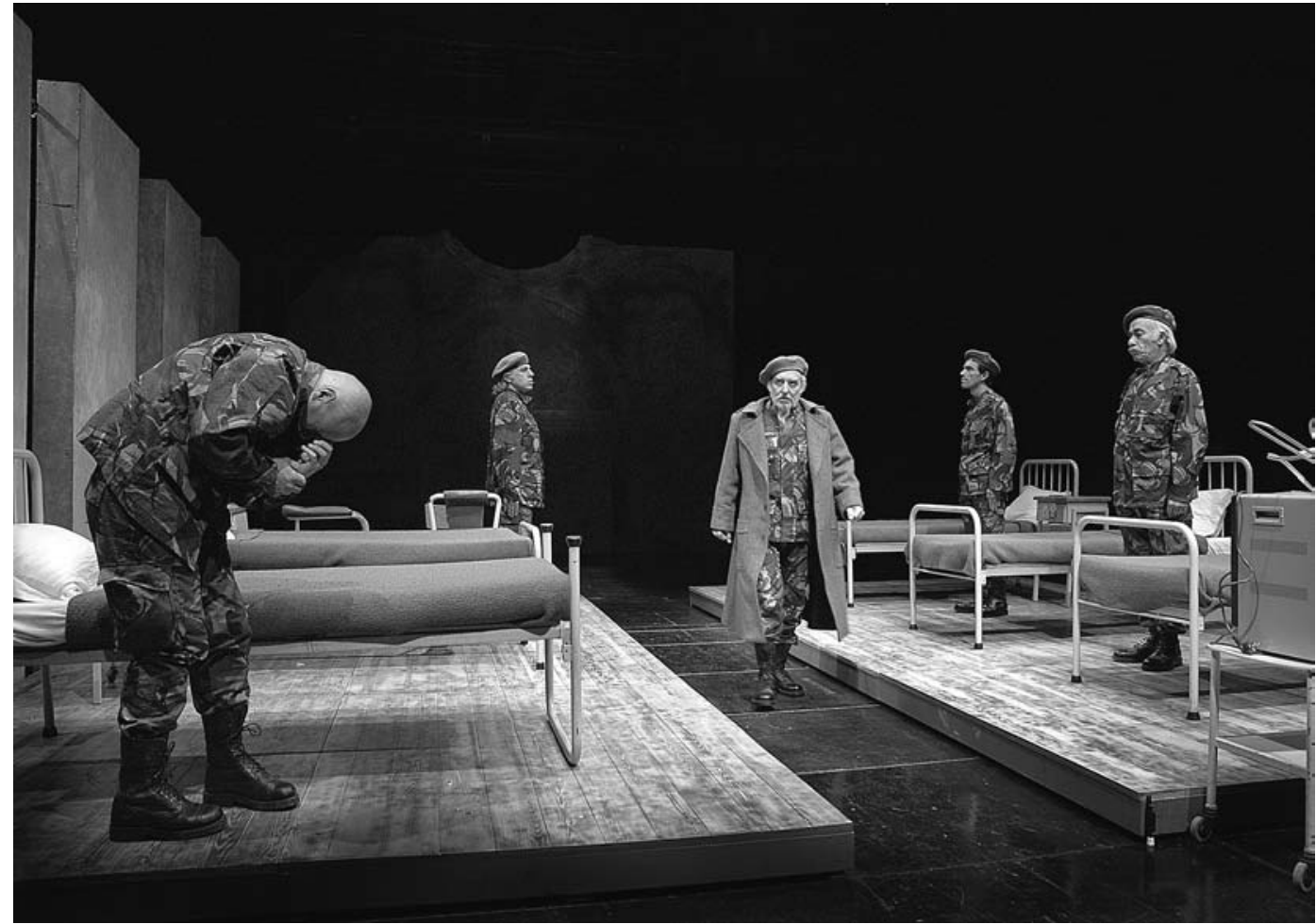

\title{
Realidade e ficção em tempo de guerra
}

\section{Christine Zurbach}

Titulo: O coronel pássaro (1993). Autor:Hristo Boytchev. Encenação/Tradução: Fernando Mora Ramos. Cenografia/Figurinos: José Carlos Faria. Música: Carlos Alberto Augusto. Iluminação: António Plácido. Assistente de encenação: Octávio Teixeira. Video: José Henrique Caldeira. Intérpretes: Pedro Ramos, Isabel Lopes, Carlos Borges, Jorge Estreia, José Eduardo, Vitor Correia, Victor Santos, António Plácido, Octávio Teixeira, Raquel Monteiro. Co-produção: Teatro da Rainha, CCB, Odivelcultur-Teatro da Malaposta, Al-Masrah. Local e data de estreia: Centro Cultural de Belém, Lisboa, 08 de Março de 2007.

Com a encenação da peça 0 coronel pássaro' a temática da guerra volta ao repertório da companhia do Teatro da Rainha pela mão do encenador Fernando Mora Ramos. $\mathrm{Se}$, no passado, era mostrada a partir do desengano e do sofrimento do camponês Ruzzante inventado por Ângelo Beolco para uma obra dramática contextualizada nos episódios bélicos que atravessaram toda a Itália (e a Europa) renascentista, a imagem ficcionada dos efeitos da violência exercida no indivíduo e no grupo pela guerra surge, no mundo de hoje, em concorrência com a realidade diariamente presente nas reportagens que alimentam os meios de comunicação.

Na verdade, as relações entre ficção e realidade raramente viveram uma crise tão profunda como a que se instalou em todas as artes no mundo contemporâneo. Ao dividir os criadores no plano das suas opções estéticas e ideológicas, a situação actual leva alguns, mais comprometidos (ou engagés, na expressão popularizada por Sartre num tempo igualmente dificil), a pronunciaremse pela justeza de uma prática artística que "toma partido" e pretende dar resposta à pergunta que a todos se coloca: que pode a arte, e em particular o teatro, num universo em que o real e o virtual se apresentam tão semelhantes a ponto de se confundirem e, sobretudo, de confundirem os mais desatentos? Num regresso a uma vocação antiga nascida com os Gregos, o espectáculo 0 coronel pássaro pertence sem equívoco ao/a um teatro que (ainda) se interroga sobre a vida em comum dos homens.

Assim, para o Teatro da Rainha, inscrever Hristo Boytchev no seu repertório, em estreia absoluta em Portugal, corresponde a uma opção programática que, como para o dramaturgo, vai claramente no sentido da presença actuante do teatro no mundo. Para tal, Boytchev utilizou recursos que valem pela sua simplicidade e eficácia e que as opções da encenação retomam e aproveitam com pertinência. 0 primeiro consiste no facto de contar uma fábula teatral, não-realista, a partir do modelo convencional de uma narrativa teatral construida na forma de um díptico; o segundo é o diálogo dramatúrgico de natureza intertextual que situa a peça na filiação dos autores e das obras que, de maneira diversa, também se debruçaram sobre "o modo como vai o mundo". ${ }^{2}$

Num tom tragi-cómico, e também poético, a acção da peça é recortada pela montagem de cenas breves de escrita cinematográfica, ${ }_{1}^{3}$ com personagens individualizadas que, entre loucos e (talvez) normais, protagonizam no interior profundo de um provável país balcânico, cercadas pelos lobos, uma situação irreversivel de alheamento e abandono apenas interrompida momentaneamente pela chegada de um bem-intencionado jovem médico,

prometido ele também ao enlouquecimento. Mas a situação é bruscamente alterada com a cura repentina de um deles.
O coronel pássaro de Hristo Boytchev, enc. Fernando Mora Ramos, Teatro da Rainha, CCB, Odivelcultur-Teatro da Malaposta, Al-Masrah, 2007 (Jorge Estreia, Carlos Borges, Victor Santos, Vitor Correia e José Eduardo), fot. Paulo Nuno Silva.

0 programa que acompanha o espectáculo informa que a peça surgiu primeiramente no formato de um guião para um filme epónimo subsidiado pelo Estado búlgaro em 1996. Representada até hoje em 27 paises, obteve, em 1997, o prémio de escrita dramatúrgica, a nivel mundial, atribuido pelo British Council na categoria de Melhor Peça

Internacional, tendo sido seleccionada de entre 400 textos. 0 prémio foi

entregue ao seu autor por Harold Pinter no Royal National Theatre de Londres. Também foi apresentada em 1999 no Festival d'Avignon pela companhia do Théâtre de la Commune d'Aubervilliers e venceu no mesmo ano o prémio de Teatro Italiano "Enriço Maria Salerno" na categoria de dramaturgia europeia.

${ }^{2}$ No programa refere-se 0 cruzamento da escrita dramática de Boytchev com o comentário humoristico da vida politica num programa televisivo em que participa a partir de 1990 e no seu próprio programa criado em 1996 Também foi candidato à presidência da República da Bulgária aproveitando o tempo de antena para realizar um happening político-cómico durante 30 dias em prime time.

30 dramaturgo tem uma formação em teatro adquirida na Academia Nacional de Artes Teatrais e Cinematográficas búlgara. 
\begin{tabular}{l|l|l|l|l} 
cento e quatro & Sinais de cena 7.2007 $\mid$ Passos em volta & Christine Zurbach & Realidade e fição em tempo de guerra
\end{tabular}
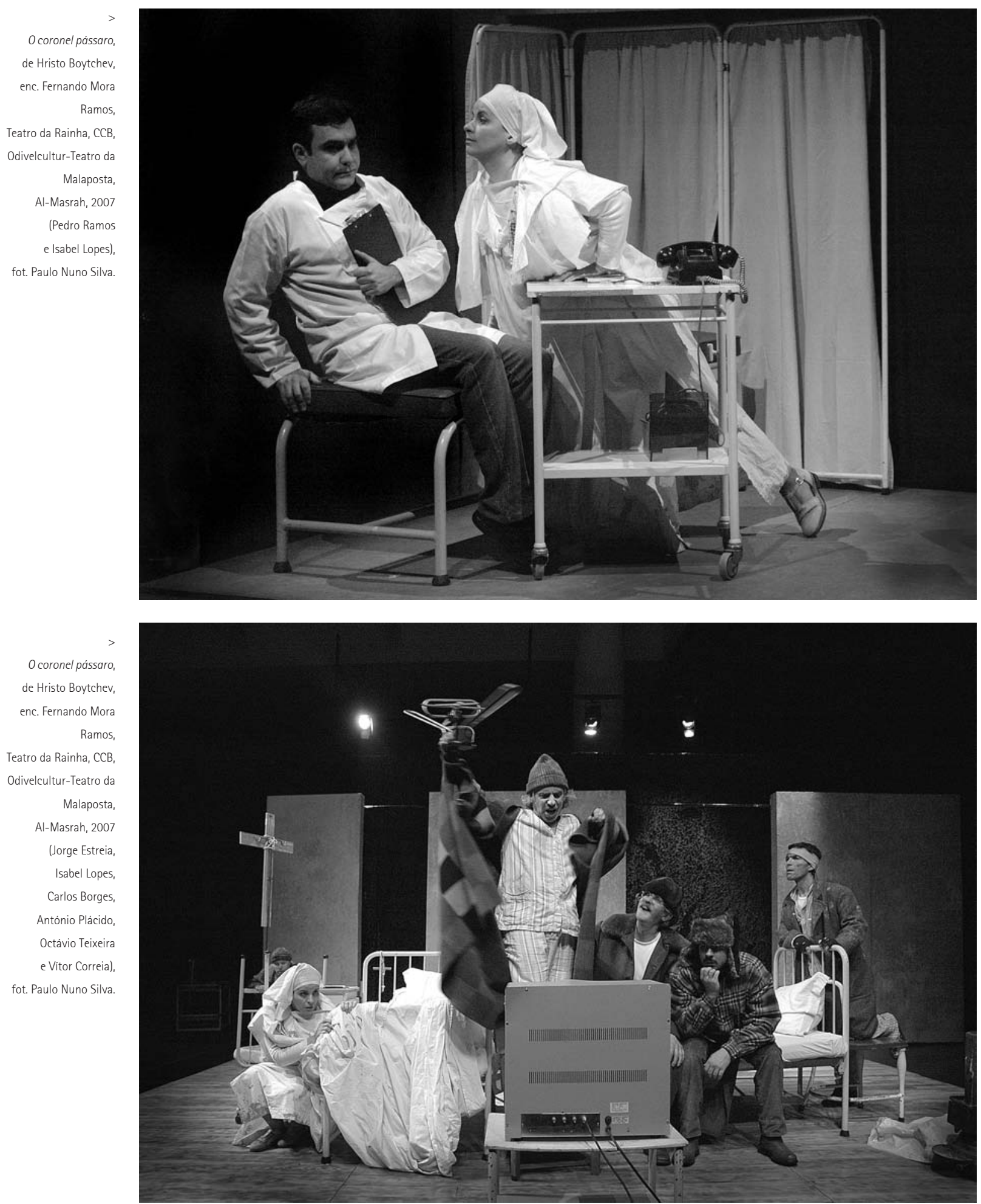

${ }^{4} 0$ hino tem letra (segunda a conhecida técnica de escrita em "verlan") de Fernando Mora Ramos e execução musical de: saxofones, Rita

Nunes; clarinete, José Conde; trompete, Emilia Santos; trombone, André Conde; tuba, Fabien Filipe; percussão, Carlos Alberto

Augusto.
0 espaço caótico inicial que figura uma sala de um manicómio degradado transforma-se no espaço agora regenerado de um quartel onde vigora uma nova ordem, a de um sistema militar e disciplinado, e que passa a ser o berço de uma nova nação, promovendo os loucos a normais na pele de separatistas fundadores da Boytchévia que se mune de imediato - num primeiro gesto de afirmação -, com o seu próprio hino. ${ }^{4}$

A peça vive como parábola da recente História europeia e para isso concorrem os meios teatrais utilizados, com um cenário funcional que sinaliza as duas vertentes do quadro da vida quotidiana dos habitantes desse conventohospício-quartel: a desordem da sala de internamento e das camas de ferro, substituída na segunda parte pela arrumação e limpeza da caserna. Do mesmo modo, o guarda-roupa materializa esses dois momentos recorrendo a apontamentos realistas, que passam pelos pijamas dos internados e o lençol em jeito de vestes de freira da única mulher do grupo, e seguidamente, pelas fardas de combate dos loucos agora promovidos a militares... Os adereços são, também eles, marcadamente realistas, inclusive no seu tratamento, e contribuem para suscitar uma aproximação 
pelo espectador do quadro criado com um mundo não ficcional, o dos excluídos e dos sem-abrigo. Numa luz de tonalidade fria e cinzenta, própria de um quadro de sobrevivência desumanizada, as cenas desenvolvem-se no recorte espacial criado pelo estrado de madeira, que aqui surge como um instrumento conotado com o jogo de estética brechtiana e com o teatro dito de intervenção.

Neste tipo de palco o jogo dos actores é valorizado e objectivado, tornando também evidente a coesão do elenco, composto pelo pequeno núcleo estável da companhia ao qual se juntaram colaboradores regulares e estreantes, em sintonia com o discurso teatral da companhia. Por exemplo, no caso de 0 coronel pássaro, em que as personagens entram e se apresentam - ou descrevem - sucessivamente ao médico dando a conhecer as suas fobias e complexos diversos, a sua apresentação indirecta e distanciada recorre a uma prática de jogo não psicológica, que permite a reflexão crítica sobre a verdade da sua dimensão psiquiátrica, como é sugerido no programa da peça: "Se pensarmos que uma obra de ficção não tem que respeitar leis imitativas, fotográficas e documentais, podemos imaginar que a loucura que na peça é reconstruida algo deve à loucura real". Mas se é aquela que se pode observar eventualmente na sociedade actual, ela acaba por surgir como muito mais saudável que a normalidade oferecida pelo universo militar. A segunda parte mostra, num contraste violento, a entrada trágica dos loucos no mundo que observavam na televisão, religiosamente presente através do mesmo noticiário, sistematicamente repetido, sobre genocidios e acções de guerra que, também presenciados pelos aldeões, são usados como moeda de troca por alimentos e lenha. A fábula termina com a imagem pessimista e sem retorno do "tornar-se idêntico", até pela troca de vestuáriofardamento, num final que transcende o modo tragicómico que atravessou toda a peça. No coronel pássaro, o efeito cómico, por ser motivado pelo espectáculo não politicamente correcto da demência na primeira parte, é mais desconcertante para o espectador, afinal, do que o grotesco aparato do exército da nação recém criada: não estaremos já mais acostumados à representação do desumano na sua farda bélica do que sensiveis à verdadeira e frágil humanidade dos loucos e dos desprotegidos? A pergunta anterior, sobre o que pode o teatro, a peça de Hristo Boytchev responde suscitando tal interrogação.

0 segundo recurso, constituido pela intertextualidade estruturante da peça, que referimos anteriormente, vem apoiar a justeza dessa preocupação que não poderia ser apenas uma marca da dramaturgia do nosso tempo, mas é certamente uma componente importante da dramaturgia de Boytchev. É descrita detalhadamente no esclarecedor caderno-programa do espectáculo onde lemos que "(...) 0 coronel pássaro se estrutura a partir de uma multiplicidade de influências e isso faz as suas características", fazendo do texto "uma peça em que é dificil descortinar as fronteiras referentes, elas são múltiplas e constituem-se como um novo corpo". São Gorki, Brecht, Shakespeare com o seu Hamlet e Büchner com Woyzeck, mas também Tchekov, Strindberg, Beckett, ou o absurdo monstruoso de lonesco. Mas o valor principal desse traço textual e estilístico, marcado por uma erudição teatral bem patente nos textos publicados no programa - que confirmam a seriedade do trabalho dramatúrgico feito habitualmente no Teatro da Rainha -, encontra-se essencialmente na sua apropriação pela própria encenação onde o jogo intertextual surge claramente, por exemplo, no modo alusivo ou sugestivo como é tratado pelos actores que, com humor e inteligência, o enriquecem e recriam de maneira pessoal.

0 resultado é um espectáculo ao mesmo tempo sério e leve. Leve no tom próprio de quem conta uma história com loucos, sério pela atitude comprometida e crítica de quem o apresenta hoje num contexto de "irracionalidade global" - expressão que Mora Ramos substitui à de globalização... - e de desamor pela arte discursivamente responsável. Os dramaturgos do passado, que como Sófocles criaram figuras marginais à lei desumanizada da sociedade, como a de Antígona, ecoam nesta peça onde aparecem não como prazer erudito e gratuito, mas para serem reinterpretados. Numa (talvez) Bósnia destruída pela guerra, ou apenas num manicómio à deriva e que procura manter um elo ilusório com o real através da actualidade do pseudo-noticiário da TV, o médico e os outros têm uma repentina esperança nos pássaros... E é nesse passo, talvez o mais próximo na sua emocionalidade de uma dimensão trágica, que o espectador não pode deixar de recordar o vazio de um céu onde já não se encontra ninguém como nos ensinam os mais lúcidos filósofos dos tempos que decididamente passaram a ser os nossos. Restará ao teatro a tarefa de assegurar a continuação do trabalho daqueles que, como Boytchev, também dele se serviram para manifestar a sua inquietação e perplexidade perante o mundo, com ou sem loucos. 